LBNL Report 43408

\title{
SHORT-TERM AND LONG-TERM VADOSE ZONE MONITORING: CURRENT TECHNOLOGIES, DEVELOPMENT, AND APPLICATIONS
}

\author{
Boris Faybishenko \\ Lawrence Berkeley National Laboratory \\ Berkeley, CA 94720 \\ Tel: 510-486-4852, FAX 510-486-5686, bfayb@lbl.gov
}

\begin{abstract}
At Hanford, Savannah River, Oak Ridge, Idaho National Engineering and Environmental Laboratory (INEEL), and other DOE sites, field vadose zone observations have shown complex water seepage and mass transport behavior in a highly heterogeneous, thick vadose zone on a variety of scales. Recent investigation showed that severe contamination of soils and groundwater by organic contaminant and nuclear waste occurred because of water seepage and contaminant transport along localized, preferential, fast flow within the heterogeneous vadose zone. However, most of the existing characterization and monitoring methods are not able to locate these localized and persistent preferential pathways associated with specific heterogeneous geologic features, such as clastic dikes, caliche layers, or fractures. In addition, changes in the chemical composition of moving and indigenous solutes, particularly sodium concentration, redox conditions, biological transformation of organic materials, and high temperature, may significantly alter water, chemicals, and bio-transformation exchange between the zones of fast flow and the rest of the media. In this paper, using the data from Hanford and INEEL sites, we will (1) present evidence that central problems of the vadose zone investigations are associated with preferential, fast flow phenomena and accelerated migration of organic and radioactive elements, (2) identify gaps in current characterization and monitoring technologies, and (3) recommend actions for the development of advanced vadose zone characterization and monitoring methods using a combination of hydrologic, geochemical, and geophysical techniques.
\end{abstract}

\section{Introduction}

Vadose zone characterization and monitoring is essential for several major DOE environmental restoration needs, such as:

(1) a complete and accurate assessment of the inventory, distribution, and movement of contaminants in the unsaturated-saturated soils and rocks,

(2) development of improved predictive methods for liquid flow and contaminant transport,

(3) design of remediation systems (barrier systems, stabilization of buried wastes in situ; cover systems for waste isolation, in situ treatment barriers of dispersed contaminant plumes, bioreactive treatment methods of organic solvents in sediments and groundwater); and

(4) chemical treatment technologies to destroy or immobilize highly concentrated contaminant sources (metals, radionuclides, explosive residues, and solvents) accumulated in the subsurface.

More than $50 \%$ of the DOE's facilities and $35 \%$ of the waste sites have radionuclide and metal contamination in soils and sediments. Contaminants leaking from highly alkaline, high-level waste 
storage tanks at a number of DOE sites flow through preferred path channels into groundwater, where they represent an increased human and environmental risk. For example, the investigation of the effect of subsurface heterogeneity on chemical reaction and transport is a high priority problem at Hanford (Hanford Site Science Need Identification No. RL-SS29-S, 1998). A key issue facing DOE's environmental restoration managers is the development of appropriate conceptual models of water flow and chemical transport in the soil-rock formation in the vadose zone, taking into account the processes of preferential and fast water seepage and contaminant transport toward the underlying aquifer. These processes are enhanced under episodic natural precipitation, snowmelt, and waste leaks from tanks, cribs, and other surface sources. However, until recently, effects of episodic infiltration and preferential flow on a field scale have not been taken into account in predicting flow and transport and developing remediation procedures. The pronounced temporal and spatial structure of water seepage and contaminant transport, which is difficult to detect, poses unique and difficult problems for characterization, monitoring, modeling, engineering of containment and remediation of contaminants. Lack of understanding in this area has led to severely erroneous predictions of the contaminant transport and incorrect remediation actions. The objectives of this paper are:

(1) Using the data from two DOE sites - Hanford and INNEL, and several other sites throughout the world, present evidence that a central problem of the vadose zone investigation is associated with preferential, fast flow phenomena and accelerated deep contaminant transport toward the groundwater, and

(2) Recommend actions for the development of both expedited and long-term characterization and monitoring methods for vadose zone investigations, which will take into account different physical, chemical, and biological processes affecting water seepage and contaminant transport.

\section{Evidence of Preferential Flow in Heterogeneous Soils and Fractured Rocks}

Term Definition. The term preferential flow is used to describe the flow that occurs in a non-volumeaveraged fashion along localized, preferential pathways, bypassing a fraction of the porous space. Preferential flow in heterogeneous soils may occur along root channels, earthworm burrows, and soil fissures or cracks in both fine-textured and coarse-textured soils, as well as because of geological heterogeneity (e.g., fractures, clastic dikes, and breaks in caliche layers), created as a result of depositional conditions, diagenesis of sediments, faulting, fracturing, and differential weathering processes. Because the flow velocity is higher along the zones of preferential flow than in other parts of the media, preferential flow is also called fast flow. Water seepage in the subsurface depends on the state of the land surface, the heterogeneity of the soil profile, and characteristics of the atmospheric and artificial forcing events, which occur on different time scales.

Heterogeneous soils and sediments at the Hanford site. The sediments beneath waste sites at Hanford are highly heterogeneous (e.g., interbedded sand, silts and gravels). Temporal and spatial variations in net water infiltration through current and past liquid discharges, water line leaks, etc., and variable chemical interactions complicate description and understanding of contaminant transport, leading to uncertainty in the evaluation of transport at contaminated sites. The primary technical gaps of investigations are an insufficient understanding of source terms, geological and hydrologic properties, preferential flow, and chemical interactions, which make current modeling of contaminant transport in the Hanford vadose zone unreliable. The three potential types of preferential flow in a highly heterogeneous Hanford formation are: (1) fingering, (2) funnel flow, and (3) flow associated with clastic dikes or poorly sealed borehole annular space. According to Ward et al. [1997], funnel flow could enhance lateral migration, and horizontal layering will tend to stabilize fingered flow, while cross-bedding acts to concentrate and coalesce fingers [Glass et al., 1991; Glass and Nicholl, 1996]. Flow through clastic dikes and poorly sealed well annular spaces could exhibit a hysteretic effect that may appear during infiltration events. 
Recent reports from the Hanford reservation indicate that ${ }^{137} \mathrm{Cs}$ has penetrated "deep into the vadose zone, disproving the standard view that cesium moves only a few feet from leak locations" (Vorenberg, 1997). However, the role of liquid flow and transport through the annulus of boreholes is not clear. Conventional large-scale volume averaged flow models failed to anticipate such migration, and were described as "entirely unreliable ... garbage in, garbage out" by an expert panel convened by the DOE (Vorenberg, 1997). The Hanford Panel Statement of December 17, 1996, points out that neither the early gamma spectral logging data nor gross-gamma logs provided explicit evidence that ${ }^{137} \mathrm{Cs}$ has moved deep within the vadose zone. Although there may not be a broadly dispersed plume of ${ }^{137} \mathrm{Cs}$ in the vadose zone, it is likely that contaminants are reaching the groundwater through narrow formation pathways. Important Hanford geochemical problems to be investigated are: (1) the colloid-facilitated transport of plutonium and the facilitating effects of solvents and complexants, (2) the existence of heterogeneous reduction and inter-particle diffusion, which potentially affect technetium immobilization in the vadose zone, and (3) the extent of fixation of sorbed cesium-137 and strontium-90 by sediments.

Fractured basalt at the INEEL site. Percolation ponds, injection wells, and buried waste sites are primary sources of the fractured basalt vadose zone contamination at the INEEL. The Radioactive Waste Management Complex (RWMC) includes one of the largest subsurface waste disposal facilities in the DOE complex. Past disposal of low-level, mixed, and transuranic radioactive wastes occurred by direct discharge or burial in shallow, unlined pits and trenches within the surficial sediments. The vadose zone fractures provide a mechanism for deep transport of oxidizing fluid and gas, leading to enhanced release of toxic species such as heavy metals which may otherwise be stable in a reducing environment. Flooding of the RWMC has occurred three times in the past, potentially increasing the downward mobility of the subsurface contaminants. The determination of the time required for contaminants to reach the aquifer is important in decision making regarding remediation options. In 1994, the INEEL conducted the Large Scale Infiltration Test (1.4 kilometers south of RWMC) to investigate hydrologic properties of the vadose zone basalts. The vadose zone thickness near the RWMC is about $190 \mathrm{~m}$. The LSIT site consisted of a bermed basin $183 \mathrm{~m}$ in diameter, which contained 32 million liters of water during the test. Beneath the basin is a thick sequence of stacked basaltic lava flows, with the first major interbed at a depth of $55 \mathrm{~m}$. Seventy wells were drilled for the test primarily along four axes extending radially from the basin, with most terminating in the sedimentary interbed. During the LSIT, tracers did not always follow the same pathways as the initial water movement. The tracer distribution could not be modeled as a onedimensional steady-state flow, but rather as a three-dimensional network of flow paths, which may vary in time (Wood and Norrell, 1996; Faybishenko et al., 1999b).

Other sites. The observations at Hanford and the INEEL are in line with an increasing body of field evidence from various sites in semi-arid regions in the U.S.A. (e.g., Yucca Mountain (Flint and Flint, 1995), INEEL (Faybishenko et al., 1999a; 1999b; Podgorney and Wood, 1999), Arizona (Wierenga et al., 1998), New Mexico (Wierenga et al., 1991; Hills, 1991)) and throughout the world (e.g., Australia (Allison, 1988), Israel (Nativ et al., 1995)). These investigations show that water seepage occurs in an episodic manner along localized preferential pathways at depths of several hundred meters beneath the land surface. It is important that only portions of fractures carried water, and the chemical composition of water obtained from fractures was substantially different from that of water samples extracted from the nearby rock matrix (Eaton et al., 1996). At a field site in the Negev Desert, Israel, man-made tracers were observed to migrate with velocities of several meters per year across a 20-60-m-thick unsaturated zone of fractured chalk (Nativ et al., 1995).

Mechanisms of Preferential Flow and Accelerated Chemical Transport. Several mechanisms are assumed to cause preferential flow, such as water repellency, cracks, biological effects (such as earthworm or root channels and macropores), air entrapment, small-scale variations in soil hydraulic properties and discrete obstacles, entrapped air behind of the wetting front, and confined air ahead of the wetting front. Field infiltration tests with tracers showed that the volume of wetted soils within fingers could occupy from $2 \%$ (Kung, 1990) to $20-70 \%$ (Jury et al., 1986; Ghodrati and Jury,1990). The knowledge of this volume is important in predicting the fate of contaminants. Small differences in surface topography may significantly affect spatial variations of infiltration, which occur as a result of non-uniform 
snowmelt on the land surface and changes in soil hydraulic properties in the near-surface zone resulting from temperature variations. Preferential flow in the vadose zone creates localized groundwater recharge, which may vary with time as a result of changes in the chemical composition of moving and indigenous solutes. For example, sodium concentration, redox conditions, biological transformation of organic materials, and high temperature, may significantly affect hysteretic properties of water retention and unsaturated hydraulic conductivity of unsaturated-saturated soils, as well as the processes of water, chemicals, and bio-transformation between the zones of fast flow paths and slow volume-averaged flow.

The capillary characteristics of the heterogeneous sands play a critical role in the displacement of water by a dense, immiscible phase, chlorinated solvent (DNAPL) (Chen et al., 1995; Ewing and Berkowitz, 1998). The invading DNAPL may flow laterally and cascade off of fine-sand lenses (Kueper et al., 1989). Chilakapati et al. (1998) showed that the prediction of geochemical transport in heterogeneous systems using a volume averaged model significantly underestimated oxidation $(74 \%)$, the reaction kinetics, and retardation.

\section{Current Technologies and Technical Gaps Associated with their Applications}

It is common practice to install an array of single monitoring probes in boreholes at different depths within fine-sand layers, separated by impermeable bentonite or cement (Everett et al., 1984). However, these materials may settle unevenly in the borehole, creating air pockets, as well as absorb water from the surrounding formation (or the access water may wet the formation). If a water-conducting pathway intersects the well sand layer, water may accumulate around the monitoring probe or perch on top of a bentonite seal, producing erroneous measurements of water flow. An application of the widely used FLUTE liners at DOE sites (Keller, 1991; 1998; Williams et al., 1995) requires a careful design and maintenance to provide a good contact between the liner and soils.

To monitor flow and transport in the vadose zone, we may use point-type probes, such as tensiometers, time domain reflectometry probes (TDR), suction lysimeters, and thermistors; as well as geophysical imaging methods, such as seismic surveys, ground penetrating radar (GPR) and 3-D electrical resistivity tomography (ERT) (Hubbard et al., 1997; Majer et al., 1997). The point-type probes may or may not intersect single flow paths (Figure 1). The shortcoming of point-type probe measurements is the difficulty of combining their responses in a meaningful way, such as integrating or volume averaging responses from a number of point measurements. Geophysical imaging methods complement point-type measurements by providing a spatially distributed view of subsurface conditions. Each measurement represents an average over space and time; however, the volume affected cannot be determined. The shortcoming of geophysical methods is their lack of spatial resolution in detecting small wetted zones, and the difficulty of correlating electromagnetic responses, seismic velocities, etc., to hydrogeologic parameters governing fluid flow. Neither method can be used to observe flow in single fractures or fluid movement at the fracture-matrix interface in sufficient detail to accurately represent transport. Because field measurements provide only average characteristics of the rock and fracture properties over space and time, the actual resolution of the measurements and the volume of rock involved in averaging remain unknown. It is also important to keep in mind that, in contrast to porous media, different geological, mechanical, and geochemical processes govern the physics of flow in different component of fractured rocks, such as fractures and matrix. The wide variety of processes controlling flow in fractured basalt at different scales makes conventional scaling procedures inapplicable. 


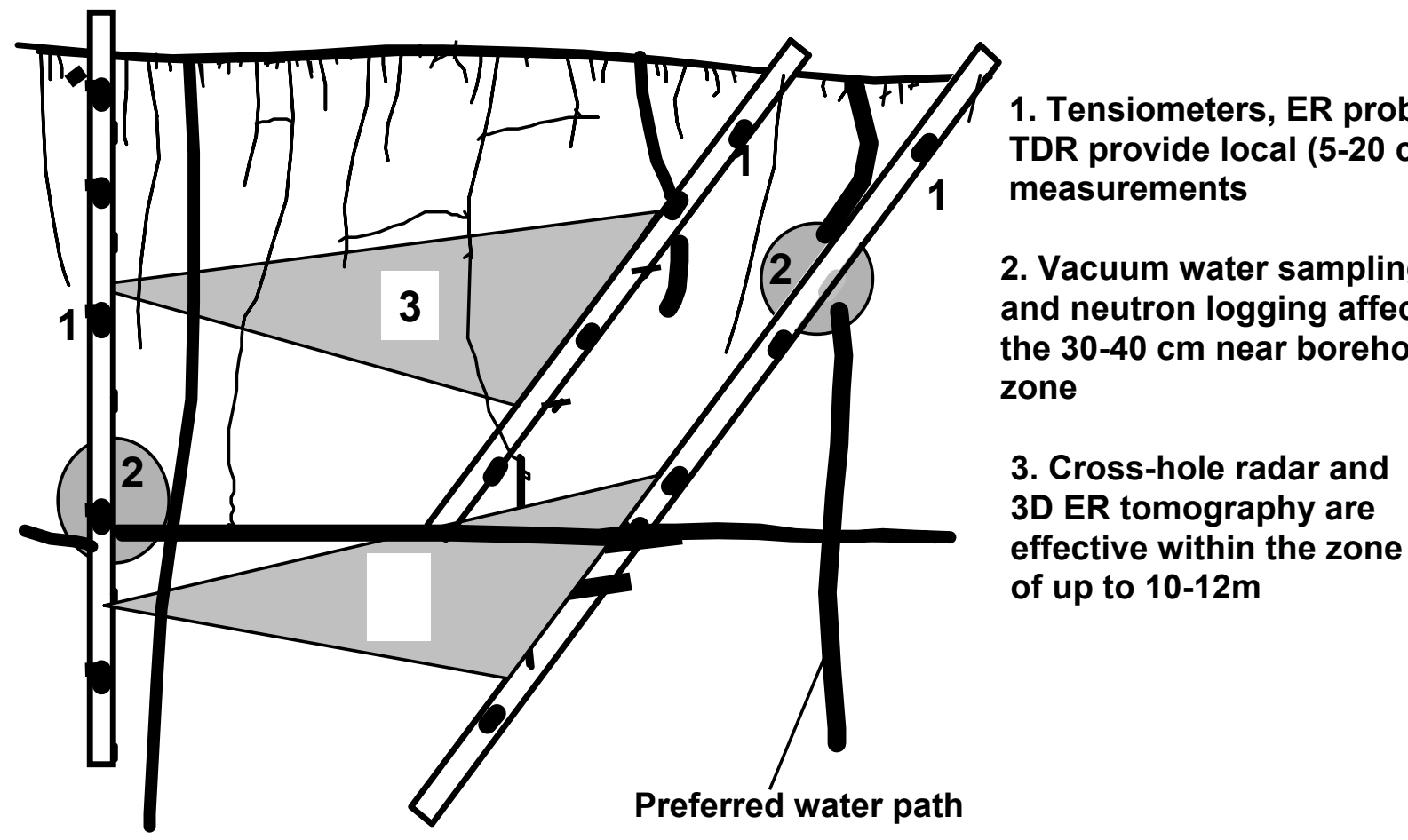

Figure 1. Schematic of the performance of local-type and cross-borehole monitoring methods in a heterogeneous formation (Faybishenko et al., 1999)

Small changes in the water flow regime of a heterogeneous deep vadose zone may not be detected using conventional moisture content measurements (for example, neutron logging) because the accuracy of measurements is within the range of moisture content fluctuations. Local-type measurements can be provided using tensiometers that are commonly used under both laboratory and field conditions for measuring the water pressure in variably saturated media. However, conventional tensiometers cannot be used at depths greater than about 5-7 meters (Stephens, 1996). The advanced tensiometer developed by Hubbell and Sisson (1998) has no remote control over water level in the tensiometer and cannot be calibrated in situ. Faybishenko (1999) designed a two-cell tensiometer having a porous tip at the bottom, and an inverted solid cup some distance from the ceramic tip, and used it for measurements at the Box Canyon site in Idaho.

Suction lysimeters, commonly used to collect pore solution samples, may collect water from a certain volume of soils that depends on the presence of nearby preferential flow zones. The small size of the lysimeter pores may not permit collection of fluid samples for a bacteriological analysis.

Water-balance lysimeters used to investigate the water balance in the near-surface vadose zone may create an artificial one-dimensional flow pattern along the length of the lysimeter, which does not relate to the natural three-dimensional flow pattern in undisturbed soils and sediments. If the field lysimeters are cut off at the bottom, it is difficult to maintain a lower boundary condition that will correspond to natural conditions.

Direct measurement of hydrologic and chemical parameters are problematic, because the fluxes are low and changes in these parameters are small and often within the accuracy of measurements (Allison, 1988). The measurements should be taken over several years in order to estimate long-term trends in hydrologic and geochemical characteristics of soils (Hutter, 1996; Sullivan et al., 1996). 
Thus, in spite of an enormous body of research literature and numerous ASTM standards, there is no general approach to the investigation of the vadose zone, nor is there a general theory for estimating 3D variability of soil hydraulic properties. Previously employed methods of characterization and monitoring do not cover essential hydrological and geochemical processes affecting water seepage and contaminant migration in unsaturated soils and rocks. Each site requires special investigation.

\section{Recommendations for Future Development}

The development of improved characterization and monitoring methods for contaminated sites with heterogeneous soils and sediments should address the following problems, which are relevant to predicting and managing remediation of contaminated sites with heterogeneous soils and sediments on different scales:

- What are important measurable vadose zone parameters affecting the initiation of preferential flow in the vadose zone?

- How can one determine the spatial extent of soils and sediments affected by preferential flow and what is the frequency of preferred paths?

- How can one measure the water velocity and concentration flux within the zone of preferential flow?

- How do preferential, fast flow within water fingers affect chemical reactions, and how can these processes be measured in the field?

- How do biogeochemical and hydrochemical reactions affect unsaturated chemical transport, solute attenuation, chemical and mineralogical speciations, colloidal transport, and binding of contaminants on mineral surfaces?

- How to study the impact of extreme waste chemical conditions (high acidity, basicity, ionic strength, etc.) on water seepage and contaminant mobility in the vadose zone?

In order to bridge the gap between the vadose zone specific needs, we recommend focus on the development of several emerging technologies, including: borehole completion in unstable and fractured rocks; installation of instrumentation in contact with the most important geological features of the formation; application of conservative and reactive tracers (choice of environmentally safe conservative and nonconservative tracers could include $\mathrm{SF}_{6}$, microspheres, magnetic liquids, $\mathrm{KBr}$, isotopes ${ }^{3} \mathrm{H},{ }^{2} \mathrm{H}$, ${ }^{18} \mathrm{O}$, etc.) that can be used as surrogates to simulate the movement of organic and radioactive contaminants and their exchange between the zones of preferential flow and the soil or rock matrix; and a combination of geophysical cross-borehole tomography and local-type measurements. For example, we propose to further develop a combination of FLUTE liners (Keller, 1998) with polyurethane packers for well completion (Faybishenko et al, 1998; Zawislanski and Faybishenko, 1999). This technology shows great promise in enabling the rapid, cost-effective installation of sensors and probes. In addition, because polyurethane has low electrical conductivity, it does not affect the performance of geophysical methods, such as cross-hole radar and electrical resistivity tomography. A new fast-response tensiometer for shallow and deep vadose zone and aquifer measurements was tested in the field at the Box Canyon site in Idaho (Faybishenko, 1999). New suction lysimeters for water sampling, with specially designed, remotely operated solenoids needed to reduce the headspace above the water sample collected in the lysimeter, were deployed at the LBNL and LLNL sites. New geophysical developments include a capacitor-type moisture content measurement, three-dimensional ER tomography in conjunction with radar measurements, and a combination of tensiometry and TDR technology.

In order to identify the locations of preferential flow zones, we propose to further improve several methods: (a) soil gas sampling to determine the radon $\left({ }^{222} \mathrm{Rn}\right)$ and thoron $\left({ }^{220} \mathrm{Rn}\right)$ concentrations, the ratio of which is indicative of the near-surface preferential flow zones (Hutter, 1996); (b) cone penetrometer 
measurements using sonic-CPT probing in vertical and slanted holes (Shinn, 1998) (this method was recently deployed at the 100 area at Hanford); (c) soil water and soil gas sampling using compartmental water samplers (Dahan et al., 1998), which can be installed in either vertical, horizontal, or slanted boreholes; and (d) the noninvasive geophysical surveys using Ground Penetrating Radar (GPR) and Electrical Resistivity Tomography (ERT), which may help to identify the approximate geometry of flow paths and locate seeps and perched-water bodies in the vadose zone. It is important to carefully design a series of infiltration tests under controlled conditions of episodic water supply (sprinkling, point source, ponding) with periodic injection of conservative and nonconservative tracers simulating natural precipitation and leaks from surface sources, such as tanks and cribs. Biological activity and rates of biotransformation can be determined in situ by measuring daughter products of respiration and fermentation and by direct measurements of biomass from sediment and pore-water samples and soil gas concentrations of oxygen and carbon dioxide (Hazen, 1997). And finally, an essential component of field monitoring is the development of a reliable data acquisition system (DAS) capable to collect, store, and transmit information.

The experience obtained so far suggests that field studies should be supplemented by laboratory investigations of single cores and mathematical modeling, using a combination of alternative models, in order to provide an accurate representation of infiltration dynamics. For example, identification of preferential flow zones can be provided through deconvolution of in situ measurements with an overlapping coverage, using a deconvolution computer program based on the maximum entropy method (Reginatto et al., 1997). Determination of unsaturated hydraulic parameters using ITOUGH2 inverse modeling can be provided from simultaneous measurements of water flux and water pressure at different elevations in field and laboratory conditions, taking into account hysteretic effects (Finsterle et al, 1998; Finsterle and Faybishenko, 1999).

\section{Conclusions and Potential Benefits}

Vadose zone characterization and monitoring are intended to address problems related to the leakage of organic and radioactive wastes in soils, sediments, and rocks, and obtain data to resolve the problems of remediation. Development of cost-effective remediation plans and post-closure monitoring of contaminated sites requires an improved understanding of the inventory, distribution, and movement of contaminants in the vadose (unsaturated) and saturated zones. This information can be obtained using both short-term (expedited) and long-term characterization and monitoring of water flow and reactive chemical transport. One of the challenging problems of vadose zone characterization and monitoring is the determination of preferential and fast water seepage, and contaminant fate and transport through the vadose zone toward the underlying aquifer. These effects are enhanced by episodic infiltration of organic contaminant and nuclear waste leaks from tanks, cribs, and other surface sources at DOE sites in heterogeneous soils and sediments like those at Hanford, Savannah River, and Oak Ridge; and fractured rocks, like those at the INEEL. It has become clear that point-type measurements in heterogeneous media miss important aspects of system behavior, such as fast preferential flow, that result in severe contamination of the vadose zone and groundwater. The development of new vadose-zone characterization and monitoring methods should focus on the determination of important measurable vadose zone parameters affecting the initiation of preferential flow, the evaluation of the spatial extent of soils and sediments affected by preferential flow, and measurements of the water velocity and concentration flux within the zone of preferential flow.

Vadose zone characterization and monitoring methods should be used to:

1. predict contaminant migration and provide warning of soil and groundwater contamination before problems arise,

2. provide scientific background needed for system assessment and performance assessment,

3. select efficient remedial actions and site closure activities, and 
4. provide scientific and regulatory credibility to DOE's environmental management decision-making process to enhance protection of human health and the environment.

\section{Acknowledgment}

Some results of this paper will be included in a chapter of the DOE Vadose Book "Vadose Zone Characterization and Monitoring Methods." The work was supported by the DOE Subsurface

Contamination Focus Area of the U.S Department of Energy under Contract No. DE-AC03-76SF00098.

\section{References}

Allison, G.B., A review of some of the physical and chemical and isotopic techniques available for estimating groundwater recharge, In: I. Simmers (ed.), Estimation of Natural Groundwater Recharge, 4972, 1988.

Chen, G., M.Taniguchi, and S.P. Neuman. An Overview of Instability and Fingering During Immiscible Fluid Flow in Porous and Fractured Media. NUREG/CR-6308. U.S. Nuclear Regulatory Commission. Washington, D.C. April 1995.

Chilakapati, A., T. Ginn, and J. Szecsody, An analysis of complex reaction networks in groundwater modeling, Water Resour. Res. (34) 7, 1767-1780, 1998.

Dahan, O., R. Nativ, E. Adar, B. Berkowitz, A Measurement System to Determine Water Flux and Solute Transport Through Fractures in the Unsaturated Zone, Ground Water, 36, 444-449, 1998

Everett, L. G., Wilson, L. G., and Hoylman, E. W., Vadose Zone Monitoring for Hazardous Waste Sites, Pollution Technology Review No. 112, 1984.

Ewing, R.P., and B. Berkowitz, A generalized growth model for simulating initial migration of dense nonaqueous phase liquids, Water Res. Resour., 34(4), 611-622, 1998.

Faybishenko, B., C. Doughty, M. Steiger, J.C.S. Long, T. Wood, J. Jacobsen, J. Lore, and P. Zawislanski, Conceptual Model of the Geometry and Physics of Water Flow in a Fractured Basalt Vadose Zone: Box Canyon Site, Idaho, LBLN Report 42925. Paper submitted to Water Resour. Res., 1999a.

Faybishenko, B., P.A. Witherspoon, C. Doughty, T.R. Wood, R.K. Podgorney, and J.T. Geller, Multi-Scale Investigations of Liquid Flow in the Vadose Zone of Fractured Basalt, Paper submitted to the AGU Monograph "Flow and Transport in Fractured Rocks," LBNL Report No. 42910, 1999b.

Faybishenko, B., Tensiometer for Shallow or Deep Measurements Including Vadose Zone and Aquifers, Patent Pending, Application Number 08/843,000, Notice of Allowance 2/16/99c.

Faybishenko, B., Comparison of laboratory and field methods for determination of unsaturated hydraulic conductivity of soils, LBNL Report-42022. 1998 (To be published in the Proceedings of the International Conference "Characterization and Measurement of the Hydraulic Properties of Unsaturated Porous Media"), 1999d

Faybishenko, B., B.J. Sisson, K.Dooley, W.E. McCabe, and H.W. McCabe, Method for Borehole Instrumentation and Grouting in Rocks and Soils, Disclosure and Record of Invention submitted to the LBNL Patent Department on 9/11/98 (IB-1443), 1998.

Finsterle, S., and B. Faybishenko, Design and analysis of an experiment to determine hydraulic parameters of variably saturated porous media, Advances in Water Resources, 22(1), 431-444, 1999a.

Finsterle, S., and B.Faybishenko, What does a tensiometer measure in fractured rocks? LBNL Report41454. 1998 (In print, Proceedings of the International Conference "Characterization and Measurement of the Hydraulic Properties of Unsaturated Porous Media"), 1999b 
Flint L.E. and A.L. Flint., Shallow Infiltration Processes at Yucca Mountain—Neutron Logging Data, 198493. U.S. Geological Survey Open-file Report 95-4035. 1995.

Ghodrati, M., and W.A. Jury, A field study using dyes to characterize preferential flow of water, Soil Sci. Soc. Am. J., 54, 1558-1563, 1990.

Glass, R.J., T.S. Steenhuis, and J.-Y. Parlange. Immiscible displacement in porous media: Stability analysis of three-dimensional, axisymmetric disturbances with application to gravity-driven wetting front instability, Water Resources Research, Vol. 27, No. 8, pp. 1947-1956, 1991.

Glass, R.J., and M.J. Nicholl. Physics of gravity fingering of immiscible fluids within porous media: An overview of current understanding and selected complicating factors. Geoderma, Vol. 70, No. 2-4: 133166. 1996.

Hazen, T. C. Bioremediation. In: Microbiology of the Terrestrial Subsurface, P. Amy and D. Haldeman (eds), pp. 247-266. CRC Press, Boca Raton, 1997.

Hills, R.G., Wierenga, P.J., D.B. Hudson, and M.R. Kirkland. The Las Cruces Trench Experiment: Experimental Results and Two-Dimensional Flow Predictions. Water Resources Res., 27, 10, 2707-2718, 1991.

Hubbard, S.S., J.E. Peterson, E.L. Majer, P.T. Zawislanski, K.H. Williams, J. Roberts, and F, Wobber, Estimation of permeable pathways and water content using tomographic radar data, The Leading Edge of Exploration, 16(11), 1623-1628, 1997.

Hubbell,J.M., and J.B. Sisson, Advanced tensiometer for shallow or deep soil water potential measurements. Soil Sci. 163(4):271-277, 1998.

Hutter, A.R., Spatial and Temporal Variations of Soil Gas 220Rn and 222Rn at Two Sites in New Jersey, Environmental International, 22, 455-469, 1996.

Jury, W.A., H. Elabd, and M. Resketo, Field study of napropamide movement through unsaturated soil, Water Res. Resour., 22, 749-755, 1986.

Keller, C., Personal communication about a new technique of sonic drilling and a FLUTE liner installation at the OSCO facility in the San Gabriel Valley in eastern Los Angeles County, April 1998.

Keller, C., So, What is the Practical Value of Seamist?, Published in the Proceedings of the Fifth National Outdoor Action Conference on the Aquifer Restoration Ground Water Monitoring and Geophysical Methods, Las Vegas, May 1991.

Kueper, B.H., W. Abbott, and G. Farquhar, Experimental observations of multiphase flow in heterogeneous porous media, J. of Contam. Hydrology, 5, 83-95, 1989.

Kung, K.J.S., Preferential flow in a sandy vadose zone, 1, Field observation. Geoderma, 46, 51-58; 2. Mechanism and Implications. Geoderma, Vol. 46: 59-71. 1990b.

Majer, E.L., J.E. Peterson, T. Daley, B. Kaelin, L. Myer, J. Queen, P. D'Onfro, and W. Rizer, Fracture detection using crosswell and single well surveys, Geophysics, Vol. 62, No. 2, 495-504, 1997.

Nativ, R., Adar, E., Dahan, O., and Geyh, M., Water Recharge and Solute Transport Through the Vadose Zone of Fractured Chalk Under Desert Conditions, Water Resour. Res., 31, 253-261, 1995. 
Nicholl, M.J., R.J. Glass, and H.A. Nguyen, Wetting front instability in an initially wet unsaturated fracture, Proceedings, Fourth High Level Radioactive Waste Management International Conference, Las Vegas, NV, 1993.

Podgorney, R.K., and T.R. Wood. Observations of Water Movement in Variably Saturated Fractured Basalt and its Possible Implications on Predictive Modeling in Proceedings of Dynamics of Fluids in Fractured Rocks: Concepts and Recent Advances. February 10-12, 1999.

Reginatto, M., P. Shebell, and K. M. Miller, ISD97, A computer program to analyze data from a series of in situ measurements on a grid and identify potential localized areas of elevated activity, Environmental Measurements Laboratory, DOE EML-590, 1997.

Shinn, J.D., Sonic Cone Penetrometer Technology Testing, DOE CMST-CP, Projects For The Subsurface Contaminants Focus Area, FY98 Rainbow Book, and Personal Communication with J. Shinn at the 1999 Annual Review Meeting in Gaithersburg, MD, March 1999.

Stephens, D.B., Vadose Zone Hydrology, Lewis Publishers: Boca Raton, FL, 1996.

Sullivan, M., J.J.Warwick, and S.W. Tyler, Quantifying and delineating spatial variations of surface infiltration in a small watershed, J. Hydrology, 181, 149-168, 1996

Vorenberg, S. Panel Calls Ground Water Models a Case of 'Garbage in, Garbage out.' Nucl. Waste News, pp. 415-416, November 6, 1997.

Ward, A.L., G.W. Gee, and M.D. White. A Comprehensive Analysis of Contaminant Transport in the Vadose Zone Beneath Tank SX-109. PNNL-11463, UC-702. Pacific Northwest National Laboratory. Richland, Washington. February 1997.

Wierenga, P.J., M. Young, A. Warrick, et al., Maricopa Environmental Monitoring Site, Material of the Unsaturated Zone Monitoring Technology Transfer Workshop, Casa Grande, Arizona, February 11-12, 1998.

Wierenga, P.J., R.G. Hills, and D.B. Hudson. The Las Cruces Trench Site: Characterization, Experimental Results, and One-Dimensional Flow Predictions. Water Resources Res., 27, 2695-2705, 1991.

Williams, C., W. Lowry, D. Cremer, and S.D. Dunn. SEAMIST In-Situ Instrumentation and Vapor Sampling System Applications in the Sandia Mixed Waste Landfill Integrated Demonstration Program: Final Report. Sandia Report, SAND95-2060. September, 1995.

Wood, T. R., and Norrell, G. T., Integrated Large-Scale Aquifer Pumping and Infiltration Tests: groundwater pathways OU 7-06: summary report, Idaho National Engineering Laboratory Report INEL96/0256, 1996.

Zawislanski, P.T., and B. Faybishenko, New Casing and Backfill Design for Neutron Logging Access Boreholes, Groundwater, 30(1), 1999. 